\title{
Diversity, Distribution and Co-occurrence Patterns of Bacterial Communities in a Karst Cave System
}

OPEN ACCESS

Edited by:

Bradley M. Tebo,

Oregon Health \& Science University,

United States

Reviewed by:

Diana Eleanor Northup,

University of New Mexico,

United States

Suzanna Bräuer,

Appalachian State University,

United States

*Correspondence:

Shuang-Jiang Liu liusj@im.ac.cn

Specialty section:

This article was submitted to Microbiological Chemistry

and Geomicrobiology,

a section of the journal

Frontiers in Microbiology

Received: 17 March 2019

Accepted: 12 July 2019

Published: 06 August 2019

Citation:

Zhu H-Z, Zhang Z-F, Zhou N,

Jiang C-Y, Wang B-J, Cai $L$ and

Liu S-J (2019) Diversity, Distribution

and Co-occurrence Patterns

of Bacterial Communities in a Karst

Cave System.

Front. Microbiol. 10:1726.

doi: 10.3389/fmicb.2019.01726

\author{
Hai-Zhen Zhu',2, Zhi-Feng Zhang 2,3, Nan Zhou', Cheng-Ying Jiang',4, Bao-Jun Wang ${ }^{1}$, \\ Lei Cai ${ }^{3}$ and Shuang-Jiang Liu ${ }^{1,2,4,5 *}$
}

1 State Key Laboratory of Microbial Resources and Environmental Microbiology Research Center at Institute of Microbiology, Chinese Academy of Sciences, Beijing, China, ${ }^{2}$ College of Life Sciences, University of Chinese Academy of Sciences, Beijing, China, ${ }^{3}$ State Key Laboratory of Mycology at Institute of Microbiology, Chinese Academy of Sciences, Beijing, China, ${ }^{4}$ Research Center for Eco-Envorinmental Sciences-Institute of Microbiology, Chinese Academy of Sciences-University of Chinese Academy of Sciences, Joint-Lab of Microbial Technology for Environmental Science, Beijing, China, ${ }^{5}$ College of Resources and Environment, University of Chinese Academy of Sciences, Beijing, China

Caves are typified by their permanent darkness and a shortage of nutrients. Consequently, bacteria play an important role in sustaining such subsurface ecosystems by dominating primary production and fueling biogeochemical cycles. China has one of the world's largest areas of karst topography in the Yunnan-Guizhou Plateau, yet the bacteriomes in these karst caves remain unexplored. In this study, bacteriomes of eight karst caves in southwest China were examined, and co-occurrence networks of cave bacterial communities were constructed. Results revealed abundant and diversified bacterial communities in karst caves, with Proteobacteria, Actinobacteria, and Firmicutes being the most abundant phyla. Statistical analysis revealed no significant difference in bacteriomes among the eight caves. However, a PCoA plot did show that the bacterial communities of 128 cave samples clustered into groups corresponding to sampling types (air, water, rock, and sediment). These results suggest that the distribution of bacterial communities is driven more by sample types than the separate caves from which samples were collected. Further community-level composition analysis indicated that Proteobacteria were most dominant in water and air samples, while Actinobacteria dominated the sediment and rock samples. Cooccurrence analysis revealed highly modularized assembly patterns of the cave bacterial community, with Nitrosococcaceae wb1-P19, an uncultured group in Rokubacteriales, and an uncultured group in Gaiellales, being the top-three keystone members. These results not only expand our understanding of cave bacteriomes but also inspires functional exploration of bacterial strains in karst caves.

Keywords: karst cave, bacteriomes, community composition and abundance, bacterial diversity, co-occurrence pattern

\section{INTRODUCTION}

Karst is a topography formed by the dissolution of soluble rocks such as limestone, dolomite, and gypsum, and is characterized by underground drainage systems featuring sinkholes and caves. Karst landforms are widespread; approximately $20 \%$ of the earth's dry ice-free surface is composed of karst terrain (Ford and Williams, 1989; Legatzki et al., 2011). Caves are one of the typical features of a 
subsurface karst, developing when acidic water starts to break down the bedrock near cracks. More than 50,000 cave systems have been identified in the United States (Barton and Jurado, 2007), while China hosts a large contiguous karst landscape of ca. 550,000 $\mathrm{km}^{2}$ in extent, and seven karst clusters in south China are listed as a World Heritage Property by UNESCO. This region is recognized as the world's foremost area for karst landform development in the humid tropics and subtropics ${ }^{1}$. In particular, karst caves are mostly distributed in the southwest of the Yunnan-Guizhou plateau, of which the longest exceeds $138 \mathrm{~km}$ (Zhang and Zhu, 2012).

Because caves are characterized by darkness, low to moderate temperatures, high humidity, and limited nutrients, they can be discriminated from land surface substrates (Gabriel and Northup, 2013). Despite their oligotrophic conditions, microbial communities thrive in caves, with the average number of microorganisms growing in these ecosystems reaching $10^{6}$ cells/g of rock (Barton and Jurado, 2007). In the absence of sunlight, microorganisms in cave habitats cannot photosynthesize, and are forced to rely on alternative primary production strategies to offset the lack of an exogenous carbon source. Chemoautotrophic bacteria in a Romanian cave were found capable of fixing inorganic carbon and using hydrogen sulfide as an energy source, and their chemoautotrophic production also supported caveadapted invertebrates (Sarbu et al., 1996). Geobiological evidence in recent years suggests that subterranean karst environments might be a global sink for atmospheric methane due to processes involving microbes (Nguyễn-Thuý et al., 2017; Webster et al., 2018; Zhao et al., 2018). A better understanding of the microbial community of cave ecosystems will not only expand our knowledge of global microbial diversity, but it also provides valuable information about energy dynamics of novel community assemblages.

Early studies of cave microbiology mostly involved traditional cultivation techniques, and those bacteria strains playing a role in limestone calcification and primary nutrient production were identified (Danielli and Edington, 1983; Cunningham et al., 1995; Baskar, 2014). Attention was given in particular to cave Actinobacteria, which were regarded as a potential source of novel bioactive compounds (Axenovgibanov et al., 2016; Ghosh et al., 2017; Adam et al., 2018). The advent of new tools for the study and characterization of microbiomes greatly facilitated investigations of cave microbial community structure and functionality, rapidly advancing our knowledge of cave ecosystems (Barton et al., 2004; Ortiz et al., 2013; Wu et al., 2015). Previous investigations of microbial communities mostly focused on selected samples, such as its dripping waters (Laiz et al., 1999; Liu et al., 2010; Marques et al., 2019), cave sediments (Adetutu et al., 2012), cave wall surfaces (Pasić et al., 2010; Ortiz et al., 2013) and biofilms (Jones et al., 2010, 2012, 2014), and on how factors such as $\mathrm{pH}$ (Yun et al., 2016a), nutrition (Cloutier et al., 2017), and trace elements (Wu et al., 2015) could shape microbial communities in caves. Yet, systematic profiling of the cave bacteriomes sourced from air, water, rock, and sediment samples has not been reported.

\footnotetext{
${ }^{1}$ http://whc.unesco.org/en/list/1248/
}

It is estimated that China has hundreds of thousands of caves, but studies on bacterial communities have mainly focused on two caves, i.e., a $\sim 250 \mathrm{~m}$ long karst cave in central China (Liu et al., 2010; Yun et al., 2016a,b; Zhao et al., 2018) and a limestone cave in the western Loess Plateau (Wu et al., 2015). Recently, samples of air, water, rock, and sediment were intensively collected from eight karst caves in southwest China. The study of their mycobiomes indicated that both sample types and spatial variables were the key determinants of fungal distributions (Zhang and Cai, 2019). In this report, we focus on the features of and factors shaping the bacterial community in those same eight caves. We hypothesize that microbial communities of air, water, rock and sediment are shaped by their specific niche traits and that there are indicator microbial groups in each niche.

\section{MATERIALS AND METHODS}

\section{Sample Collection and Property Measurement}

Caves investigated in this study are located in southwest China; namely, in the Chongqing, Sichuan and Yunnan provinces, and the Guangxi Zhuang autonomous region (Supplementary Figure 1 and Supplementary Table 1). The geographic sampling area ranged from ca. $23^{\circ}$ to $30^{\circ}$ in latitude and from ca. $102^{\circ}$ to $110^{\circ}$ in longitude, with a subtropical monsoon climate. Limestone strata are abundant in the area, having a total deposit thickness of more than 10,000 m (Zhang and Zhu, 2012), readily promoting a karst landscape with the corrosion of surface and ground water.

The cave sampling strategy was described in our previous study (Zhang and Cai, 2019). In each cave, four to six sampling sites, interspersed at equal distances, were chosen along a transect. At each site, $2 \mathrm{~m}^{3}$ of air was filtered through a $0.22 \mu \mathrm{m}$ sterile polyester membrane using an air sampler (MAS100Eco, Merck Millipore, Darmstadt, Germany) at a velocity of $100 \mathrm{~L} / \mathrm{min}$ for $20 \mathrm{~min}$; $2 \mathrm{~L}$ of water was filtered through a sterile $0.22 \mu \mathrm{m}$ polyester membrane; $30 \mathrm{~g}$ of sediment was collected using an autoclaved spade at shallow depth $(1.0-5.0 \mathrm{~cm})$ after removing the surface layer $(c .1 .0 \mathrm{~cm})$ from three different spots; five pieces of rock in different orientations were sampled with an autoclaved chisel inserted into existing cracks, followed by hammer blows (Ruibal et al., 2005). All the samples were kept cold and transferred in sterile zip-lock plastic bags at $4^{\circ} \mathrm{C}$, and then stored at $-80^{\circ} \mathrm{C}$ before further processing.

Temperature and air humidity of each sampling site was measured, in situ, with a hydro thermograph (HT-853, HCJYET, Beijing, China). The $\mathrm{pH}$ value of sediment and rock samples was measured with a pH meter (FE20, Mettler Toledo, Zurich, Switzerland), for which the samples were dried, ground, and fully mixed with distilled water in a ratio of 1:2.5 (w/v) before this measurement (Sparks et al., 1996). The moisture of sediment samples was calculated after drying them at $105^{\circ} \mathrm{C}$ to a constant weight (Chen, 2003). Total organic carbon (TOC) and total nitrogen (TN) were measured using a TOC/TN analyzer (Vario TOC, Elementar, Hanau, Germany). 


\section{DNA Extraction From Samples}

Samples on a polyester membrane were washed off with sterile water and collected by centrifugation. The surface of rock samples was washed with $95 \%$ ethanol to reduce the contaminating influence of any dust and airborne spores, followed by two washes with sterile water containing $0.1 \%$ of the weak detergent Tween 20 (Ruibal et al., 2005). Pre-processed rock samples were then pulverized with a sterile mortar for DNA extractions.

DNA was extracted using the FastDNA ${ }^{\circledR}$ Spin Kit (MP Biomedicals, Solon, $\mathrm{OH}$, United States), following the manufacturer's instructions, and the concentration and purity of the extracted DNA was measured by a NanoDrop 2000 spectrometer (Thermo Fisher Scientific, Wilmington, $\mathrm{DE}$, United States). V4 variable regions of the $16 \mathrm{~S}$ rRNA gene were amplified using two universal primers, 515F $\left(5^{\prime}\right.$-GTGCCAGCMGCCGCGGTAA- $\left.3^{\prime}\right)$ and 806R (5'GGACTACHVHHHTWTCTAAT-3') (Caporaso et al., 2011), with barcodes at the $5^{\prime}$ end of the forward primer. The PCR reaction was performed in $50 \mu \mathrm{l}$ volume, containing $1.5 \mu \mathrm{l}$ of both primers $(10 \mu \mathrm{mol} / \mathrm{L}), 25 \mu \mathrm{l}$ of $2 \times \mathrm{KAPA}$ HiFi HotStart ReadyMix (Kapa Biosystems, MA, United States) and $23 \mu \mathrm{l}$ of template DNA. The PCR procedure included an initial denaturation at $95^{\circ} \mathrm{C}$ for $3 \mathrm{~min}, 32$ cycles of denaturing $(20 \mathrm{~s}$ at $98^{\circ} \mathrm{C}$ ), annealing $\left(16 \mathrm{~s}\right.$ at $\left.54^{\circ} \mathrm{C}\right)$, and extension $(16 \mathrm{~s}$ at $72^{\circ} \mathrm{C}$ ), and a final extension at $72^{\circ} \mathrm{C}$ for $1 \mathrm{~min}$. Triplicate PCR products of each sample were pooled and purified using AMPure XP beads (Beckman Coulter, IN, United States). The pooled products were quantified using the Qubit dsDNA HS Assay Kit (Invitrogen, CA, United States), and then diluted to reach an equal concentration. The libraries were indexed using the NEB Next Ultra DNA Library Prep Kit for Illumina (New England Biolabs, United States), and finally sequenced on an Illumina MiSeq PE 250 machine with the MiSeq Reagent Kit v2 (500 cycles; $2 \times 250 \mathrm{bp}$ ).

\section{S rRNA Gene Amplicon Analysis}

Sequences were demultiplexed according to their barcodes. The adapter, primer, and barcode were each subsequently removed. Paired-end sequences were merged using PEAR software (v0.9.6) with the $p$-value set at 0.01 (Zhang et al., 2014). Quality control (fastq_maxee $=0.5$ ), replication, singleton and chimera removal, and OTU (operational taxonomic unit) clustering (at 97\% similarity) were performed using USEARCH v7.0.1090 (Edgar, 2010). The corresponding OTU table, providing the abundances of bacterial taxa in different samples, was made with QIIME v1.9.0 (Caporaso et al., 2010) using the SILVA database release 132 (Pruesse et al., 2012; Quast et al., 2013; Yilmaz et al., 2014). Mitochondrial and chloroplastic DNA sequences, as well as OTUs with a total relative abundance of $<0.00001$ in all samples were discarded using customized $\mathrm{R}$ scripts. For the alpha diversity (the species richness and evenness) assessment, sequences in each sample were rarefied into the same number, and for the beta diversity (the dissimilarity among samples in terms of community composition) assessment, the OTU table was normalized using the CSS method (Paulson et al., 2013).

\section{Statistical Analysis and Visualization}

All the statistical analyses of data were performed in the $\mathrm{R}$ platform v3.4.2 $2^{2}$ with the use of its packages. Normal distributions of the data were checked with the Shapiro-Wilk test and homoscedasticity of variances was analyzed using Bartlett's test. Significant differences in the variance of parameters were evaluated with ANOVA (analysis of variance) or KruskalWallis tests; their corresponding post hoc comparisons were made using Tukey's HSD (honestly significant difference) test in the "stats" package or Dunn's multiple comparison test in the "FSA" package ${ }^{3}$.

Visualization of diversity and distribution of cave-associated bacterial communities were performed using the "ggplot2" package unless otherwise stated (Wickham, 2009). A map indicating the location of the eight sampled caves was plotted using the "maptools" package for $\mathrm{R}$ (Lewin-Koh et al., 2011). Principal coordinates analysis (PCoA) was conducted using the cmdscale function in the "vegan" package $e^{4}$ To statistically support the visual clustering of bacterial communities in the PCoA analysis, bacteriomes in different cave niches were compared using permutation-based hypothesis tests (PERMANOVA), with $n=999$ random permutations. Spearman correlations between the Shannon index and cave environmental factors was calculated using the corr.test function in the "psych" package (Revelle, 2018). The Bray-Curtis dissimilarity of cave bacterial communities was fitted with environmental factors using the envfit function in the "vegan" package. The Venn diagram was drawn using the "VennDiagram" package (Chen and Boutros, 2011). Indicators of different caves niches were predicted using the multipatt function in the "indicspecies" package, with $n=999$ random permutations (Cáceres and Legendre, 2009; Cáceres et al., 2010, 2011, 2012). Beta diversity partitioning was performed using the "betapart" package, which partitioned the diversity into component richness and species turnover (Baselga and Orme, 2012). The comparison between OTUs in air samples and the other three types of samples was conducted using "edgeR" package (Robinson et al., 2010).

To reduce network complexity, those genera with relative abundances $>0.05 \%$ in both the whole dataset and in each cave niche were selected to build co-occurrence networks (Jiao et al., 2016; He et al., 2017). Spearman's correlation coefficient between two genera was considered statistically robust if its value $(\rho)$ was $>0.6$ with a corresponding $p$-value of $<0.01$ (Barberán et al., 2011). The pairwise comparisons based on genera abundance were performed using the rcorr function in the "Hmisc" package ${ }^{5}$, and the $p$-values adjusted using the "fdrtool" package (Strimmer, 2008a,b). Co-occurrence networks, with each node representing one genus and each edge denoting a strong and significant correlation, were built using the "igraph" package; visualization of networks and calculation of network topological properties were performed using the interactive platform Gephi (Newman, 2003; Csardi and Nepusz, 2006; Newman, 2006; Bastian et al., 2009).

\footnotetext{
${ }^{2}$ https://www.R-project.org/

${ }^{3}$ https://github.com/droglenc/FSA

${ }^{4}$ https://CRAN.R-project.org/package=vegan

${ }^{5} \mathrm{http} / / /$ biostat.mc.vanderbilt.edu/wiki/Main/Hmisc
} 


\section{RESULTS}

\section{Geochemical Characteristics of the Eight Karst Caves}

The major geographical and physicochemical characteristics of sampled caves are listed in Table 1. The base rock of these caves was mostly limestone and/or dolomite. Though local residents and cave explorers occasionally entered these caves, all eight have never been accessible for massive tourist visits, and so remains pristine to a great extent. Seven of the eight sampled caves are located in mountains covered by forest, and another one (cave S7) is located in farmland area with tobacco seedlings. The average annual precipitation in the area of each cave ranged from $900 \mathrm{~mm}$ (cave Y2) to $1900 \mathrm{~mm}$ (cave G1). The temperature while sampling the caves ranged from 11.2 to $25.1^{\circ} \mathrm{C}$, reflecting a combined location variation owing to latitude as well as elevation. Caves G1 and G3 are at relatively low latitude and elevation, and their temperature was the highest among the eight caves. Nevertheless, all the caves had high humidity $(80-91 \%)$ and were alkaline ( $\mathrm{pH}$ 7.9-8.3), in accordance with the nature of their base rock. No significant differences were found in the $\mathrm{pH}$ levels among the sampled caves.

\section{Distribution and Abundance of Bacterial Taxa in Caves}

After quality control and removal of mitochondria and chloroplast sequences, a data set of 16S rRNA genes (V4 region) containing 4,772,351 clean sequences was obtained. The number of sequences from each sample ranged from 24,093 to 51,945 , with an average of 37,683 . These sequences were clustered into 11,444 OTUs based on a $97 \%$ similarity threshold, of which $97.8 \%$ were assigned bacterial phyla (Supplementary Table 2). Proteobacteria, Actinobacteria, and Firmicutes were predominant (i.e., relative abundance $>10 \%$ ) in cave microbial communities, accounting for $89.1 \%$ of the total sequences. The Proteobacteria (relative abundance $=41.1 \%$ ) were represented by the classes Gammaproteobacteria (32.4\%) and Alphaproteobacteria (7.9\%). The other two dominant phyla, Actinobacteria (37.6\%) and Firmicutes (10.4\%), were represented, respectively, by
Actinobacteria (25.2\%) and Bacilli (9.6\%) at the class levels Additionally, the archaeal phylum Thaumarchaeota as well as the bacterial phyla Gemmatimonadetes, Chloroflexi, and Bacteroidetes were also detected at relative abundances of $>1 \%$ in the cave communities (Figure 1). At a finer taxonomic level, 21 taxa at the family level each had an average relative abundance of more than $1 \%$, among which Pseudonocardiaceae and Enterobacteriaceae were remarkably abundant (Supplementary Figure 2).

\section{Assembly Patterns of the Cave Bacterial Community}

Alpha diversity of cave bacteriomes was measured by Shannon and Chao 1 indices. There was no significant difference in alpha diversities among the eight caves (Shannon: ANOVA, $p>0.05$; Chao 1: Kruskal-Wallis test, $p>0.05$, Supplementary Figure 3). However, the Chao 1 indices of sediment and water samples were significantly higher than those of rock and air samples, according to the Kruskal-Wallis test followed by Dunn's multiple comparisons $(p<0.05)$. Shannon indices confirmed that sediment samples had a significantly higher diversity than the rock and air samples did, but no significant difference was observed between water samples and the other three types of samples (Table 2).

The principal coordinates analysis (PCoA) plot revealed that bacterial communities in cave samples generally clustered in line with their cave niches (Figure 2). Members of air samples were closely clustered and clearly separated from samples of other types, while members of water samples were loosely clustered. These results indicated that as the medium for the assembly of bacterial communities, cave niches played a key role in determining cave bacterial diversity. This observation is reasonable, because different cave niches differ in their nutrient levels. Moreover, different niches also represent unique origin models as growing substrates for bacterial communities: rocks are cave-originating, with limited nutrients from water leakage or condensation of water moisture from surroundings; sediments are brought into caves from the outside environment and retained in caves, however, water and air are more apt to undergo frequent exchanges with the outside environment, as well as other niches inside the cave, due to their flow.

TABLE 1 | Environmental characteristics of the eight sampled karst caves.

\begin{tabular}{|c|c|c|c|c|c|c|c|c|}
\hline \multirow[b]{2}{*}{ Environmental factors } & \multicolumn{8}{|c|}{ Caves } \\
\hline & C1 & C2 & G1 & G3 & s7 & S8 & Y2 & Y3 \\
\hline Longitude ( $\left.{ }^{\circ} \mathrm{E}\right)$ & $108^{\circ} 00^{\prime} 02.28^{\prime \prime}$ & $108^{\circ} 00^{\prime} 02^{\prime \prime}$ & $110^{\circ} 30^{\prime} 37.93^{\prime \prime}$ & $108^{\circ} 55^{\prime} 52^{\prime \prime}$ & $105^{\circ} 08^{\prime} 21.6^{\prime \prime}$ & $106^{\circ} 52^{\prime} 42^{\prime \prime}$ & $103^{\circ} 22^{\prime} 57^{\prime \prime}$ & $102^{\circ} 50^{\prime} 31.8^{\prime}$ \\
\hline Elevation (m) & 890 & 1020 & 269 & 129 & 750 & 850 & 1870 & 1840 \\
\hline Provence & Chongqing & Chongqing & Guangxi & Guangxi & Sichuan & Sichuan & Yunnan & Yunnan \\
\hline Air humidity (\%)* & $91 \pm 2^{\mathrm{a}}$ & $91 \pm 2^{\mathrm{a}}$ & $87 \pm 4^{b}$ & $80 \pm 0^{C}$ & $91 \pm 1^{\mathrm{a}}$ & $91 \pm 1^{\mathrm{a}}$ & $85 \pm 7^{\mathrm{b}}$ & $84 \pm 3^{b}$ \\
\hline $\mathrm{pH}^{*}$ & $8.2 \pm 0.5^{a}$ & $8.2 \pm 0.5^{a}$ & $8.0 \pm 0.4^{a}$ & $8.2 \pm 0.5^{a}$ & $7.9 \pm 0.4^{a}$ & $8.3 \pm 0.6^{a}$ & $8.1 \pm 1.1^{\mathrm{a}}$ & $8.1 \pm 0.7^{a}$ \\
\hline
\end{tabular}

*Data are shown as the mean \pm standard deviation. Means labeled with different superscript lettering $(a, b$, or $c)$ indicate significant differences among caves. Statistical significances were determined by the Kruskal-Wallis test, followed by Dunn's multiple comparisons, at $p<0.05$. 
A

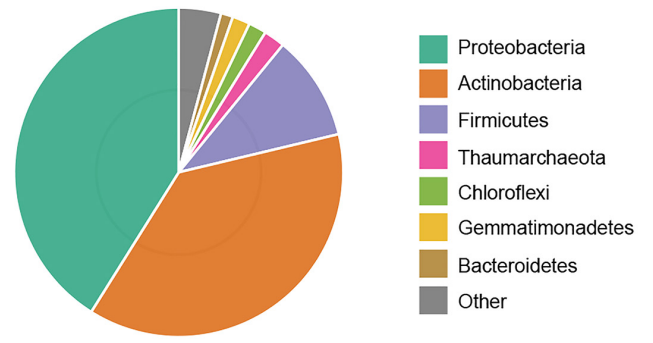

B

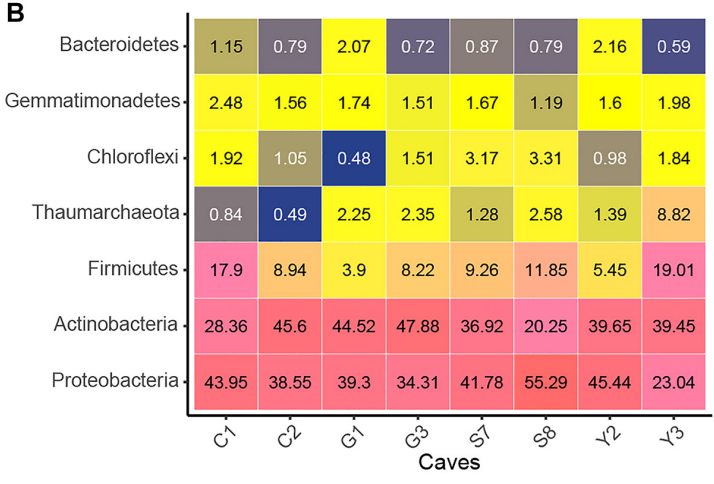

FIGURE 1 | Taxonomic composition of the karst cave bacterial community. Pie chart showing the average relative abundances of all detected phylum in the whole dataset (A). Heatmap showing the average relative abundances (\%) of the major cave bacterial phyla in each sampled cave (B); the number within each box represents the median abundance of the taxa in a given cave, taxa with low abundance are colored blue, those in higher abundance are yellow, while the highest are in pink.

To disclose the driving force of bacterial community assembly, the possible influence of cave environmental factors (Supplementary Table 3) on alpha and beta diversity was evaluated (Table 3). It was observed that temperature and air humidity significantly differentiated bacterial communities but had no significant effects on species diversity, when pooling all samples from the eight caves. But when each type of sample was analyzed separately, three results emerged: (1) Humidity showed a significant and negative correlation with the Shannon indices, while temperature and humidity statistically affected community composition, for air samples. (2) No factors tested were strongly related to Shannon indices of rock or water samples, yet TOC took a significant part in differentiating bacterial communities in their respective samples. (3) Temperature, air humidity, TOC, TN, and moisture all significantly contributed to bacterial community differentiation in sediment samples, with moisture and TN having positive and negative correlations with sediment's Shannon indices.

\section{Differences and Indicator Taxa of Microbial Community Among Cave Niches}

The taxonomic composition of bacterial groups in the four cave niches (air, water, rock, and sediment) was further evaluated (Figure 3A). Proteobacteria was the most dominant phylum in water and air samples (47.9 and 50.5\%, respectively), while Actinobacteria was the most dominant in sediment and rock samples (42.1 and $55.4 \%$, respectively). Firmicutes in air samples (25.3\%) accounted for a larger proportion of bacteria found there compared to the other three cave niches (water, rock, sediment). When the Proteobacteria in each cave niche was analyzed at the class level, Gammaproteobacteria was overwhelmingly dominant in air and water samples (44.9 and 39.6\%, respectively), Deltaproteobacteria were more abundant in water and sediment samples than in air and rock samples, and Alphaproteobacteria was more abundant in sediment than in the other three niches.

The Venn diagram revealed that OTUs differed among the four cave niches (Figure 3B). In accordance with the PCoA plot distributions, the most-clustered air samples had the greatest number of niche specific OTUs while the least-clustered water samples had the fewest number of niche-specific OTUs. A total of 6,816 OTUs were shared among all four cave niches. Although more than half of the total OTUs were present in each niche, when partitioning beta diversity into component richness and turnover, the latter accounted for the bulk of the difference found.

Air samples in cave systems are rarely studied, and they harbor unique prokaryotic communities that differ significantly from the other three, more intensively studied types of samples (PERMANOVA, $p<0.01$, Supplementary Table 4). Comparisons were then made between OTUs in air samples and other cave niches to better understand the distinctiveness of cave air's bacteriome. Most OTUs belonging to Tenericutes, Bacteroidetes, Firmicutes, and Cyanobacteria were significantly enriched in air samples; a few OTUs in Proteobacteria and Actinobacteria were significantly enriched in terms of relative abundance while others were depleted; most OTUs in Acidobacteria and other phyla were significantly depleted in air samples (Figure 4).

The IndVal analysis detected a total of 17 indicator genera that were significantly associated with different cave niches (Figure 5).

TABLE 2 | Characteristics of cave bacteria richness and diversity indices among different karst cave niches.

\begin{tabular}{lcccc}
\hline Cave niche & Observed OTUs & Coverage (\%) & Chao 1 & Shannon's index \\
\hline Air & $1161 \pm 429^{\mathrm{b}}$ & $98.4 \pm 0.8^{\mathrm{a}}$ & $1583 \pm 640^{\mathrm{b}}$ & $6.50 \pm 1.25^{\mathrm{b}}$ \\
Rock & $1129 \pm 351^{\mathrm{b}}$ & $98.4 \pm 0.6^{\mathrm{a}}$ & $1617 \pm 528^{\mathrm{b}}$ & $7.03 \pm 0.83^{\mathrm{b}}$ \\
Sediment & $1449 \pm 556^{\mathrm{a}}$ & $97.9 \pm 0.9^{\mathrm{b}}$ & $2051 \pm 776^{\mathrm{a}}$ & $7.69 \pm 1.13^{\mathrm{a}}$ \\
Water & $1484 \pm 711^{\mathrm{ab}}$ & $97.6 \pm 1.1^{\mathrm{b}}$ & $2207 \pm 1005^{\mathrm{a}}$ & $7.07 \pm 1.51^{\mathrm{ab}}$ \\
\hline
\end{tabular}

Data are shown as the mean \pm standard deviation. Means labeled with different superscript lettering (a and b) indicate significant differences between cave niches for a given index. Statistical significances were determined by the Kruskal-Wallis test, followed by Dunn's multiple comparisons, at $p<0.05$. 


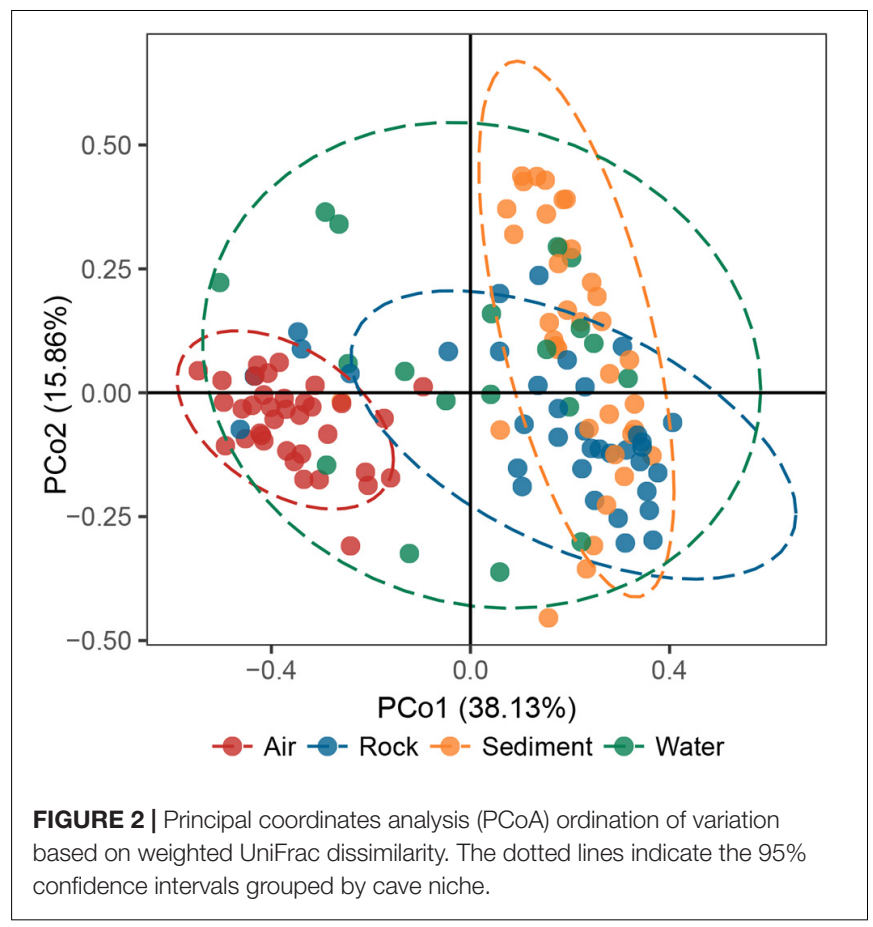

In accordance with the numbers of niche specific OTUs in the Venn diagram, water samples showed no indicator genus whereas air samples had as many as eight indicator genera. Rock samples and sediment samples overlapped considerably in the PCoA plot, and their composition patterns at the phylum level were relatively similar, yet there were still five and four indicator genera that reflected their distinctive features, respectively. Taxonomically, all indicators in rock samples belonged to Actinobacteria, and half of the indicators in air samples were Gammaproteobacteria.

\section{Co-occurrence Patterns of Bacterial Communities in the Cave Environment}

The cave bacterial network was generated for cave samples and consisted of 150 nodes (genera) and 399 edges (Figure 6). Topological properties were calculated to describe the complex pattern of inter-relationships among nodes: The average path length (APL) was 2.856 edges with a network diameter (ND) of eight edges, the clustering coefficient (CC) was 0.107 and the modularity index (MD) was 0.549. The nodes in the network were assigned to 12 bacterial phyla, among which three phyla (Proteobacteria, Actinobacteria, Firmicutes) were widely distributed, accounting for more than $83 \%$ of all nodes (Figure 6A). Based on the betweenness centrality (BC) scores, the top-three genera identified as keystone taxa were Nitrosococcaceae wb1-P19, an uncultured group in Rokubacteriales, and an uncultured group in Gaiellales.

Modules are densely-linked network regions that have more links inside than outside (Bissett et al., 2013). When the nodes were modularized, most nodes grouped into four major modules (Figure 6B), whose respective nodes showed different preferences to cave niches. For example, the majority of nodes in module 1 were the most abundant in air samples, the majority of nodes in module 4 were the most abundant in sediment samples, while nodes in module 3 were most abundant in rock or sediment samples, and nodes in module 6 were most abundant in water samples (Supplementary Table 5). This meant that bacterial communities in each niche of the caves could have had more interactions within the niche instead of outside it.

TABLE 3 | Analysis of the effect of environmental factors on karst cave bacterial diversity.

\begin{tabular}{|c|c|c|c|c|c|c|c|c|c|c|c|}
\hline & \multirow[b]{2}{*}{ Environmental factors } & \multicolumn{2}{|c|}{ Sum } & \multicolumn{2}{|c|}{ Air } & \multicolumn{2}{|c|}{ Rock } & \multicolumn{2}{|c|}{ Sediment } & \multicolumn{2}{|c|}{ Water } \\
\hline & & $\rho$ & $p$ & $\rho$ & $p$ & $\rho$ & $p$ & $\rho$ & $p$ & $\rho$ & $p$ \\
\hline \multirow[t]{8}{*}{ Shannon index } & Deptha & -0.1254 & 0.158 & -0.3242 & 0.054 & 0.1567 & 0.361 & -0.1753 & 0.299 & -0.2115 & 0.385 \\
\hline & Temperature & 0.0655 & 0.463 & 0.2868 & 0.090 & 0.1506 & 0.381 & -0.1268 & 0.455 & -0.0850 & 0.729 \\
\hline & Air humidity & -0.0424 & 0.635 & -0.3641 & $0.029 *$ & -0.1344 & 0.435 & 0.2324 & 0.166 & 0.2598 & 0.283 \\
\hline & $\mathrm{pH}$ & - & - & - & - & 0.04725 & 0.784 & -0.0702 & 0.684 & -0.0490 & 0.852 \\
\hline & $\mathrm{TOC}^{\mathrm{b}}$ & - & - & - & - & -0.0263 & 0.879 & -0.1390 & 0.419 & -0.2010 & 0.439 \\
\hline & $\mathrm{TN}^{\mathrm{C}}$ & - & - & - & - & -0.0577 & 0.738 & -0.5122 & $0.001^{* * *}$ & -0.0343 & 0.896 \\
\hline & Moisture & - & - & - & - & - & - & 0.5197 & $0.001^{* * *}$ & - & - \\
\hline & Environmental factors & $R^{2}$ & $p$ & $R^{2}$ & $p$ & $R^{2}$ & $p$ & $R^{2}$ & $p$ & $R^{2}$ & $p$ \\
\hline \multirow[t]{7}{*}{ Bray-curtis dissimilarity } & Depth $^{a}$ & 0.0058 & 0.783 & 0.0707 & 0.293 & 0.0376 & 0.513 & 0.0568 & 0.384 & 0.1459 & 0.333 \\
\hline & Temperature & 0.1052 & $0.015^{*}$ & 0.3777 & $0.001^{* * *}$ & 0.1220 & 0.120 & 0.2180 & $0.015^{*}$ & 0.2091 & 0.185 \\
\hline & Air humidity & 0.1446 & $0.002^{* *}$ & 0.3022 & $0.008^{* *}$ & 0.1680 & 0.067 & 0.2312 & $0.013^{*}$ & 0.3556 & 0.056 \\
\hline & $\mathrm{pH}$ & - & - & - & - & 0.0754 & 0.274 & 0.0298 & 0.583 & 0.2682 & 0.113 \\
\hline & $\mathrm{TOC}^{\mathrm{b}}$ & - & - & - & - & 0.2199 & $0.032^{*}$ & 0.1704 & $0.045^{*}$ & 0.5639 & $0.003^{* *}$ \\
\hline & $\mathrm{TN}^{\mathrm{C}}$ & - & - & - & - & 0.1009 & 0.183 & 0.2673 & $0.016^{*}$ & 0.0859 & 0.563 \\
\hline & Moisture & - & - & - & - & - & - & 0.4577 & $0.001^{* * *}$ & - & - \\
\hline
\end{tabular}

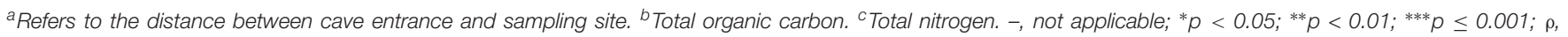
Spearman's correlation coefficient; $R^{2}$, goodness of fit; the values associated to statistically effective factors are shown in bold. 
To further illustrate the bacteria's co-occurrence patterns within each cave niche, bacterial networks were constructed separately for these four types of samples (Supplementary Figure 4), and their corresponding topological properties were also calculated (Table 4). The number of nodes and edges, clustering coefficient, and average degree were always highest in the water network, indicating that bacteria in water samples had the highest number of co-occurrences. The edge and node numbers in air networks were the least, for which the average path length was also the lowest, suggesting that bacteria in air samples were less connected but those correlated with each other were quite closely connected. Networks with small path lengths are considered to have "small-world" properties that are believed to be associated with the quick response of an ecosystem to perturbations (Watts and Strogatz, 1998; Zhou et al., 2011). This implies that bacteria in cave air maintains a small core tribe capable of strong resistance to environmental changes, a finding which deserves to be studied further in future works.

\section{DISCUSSION}

Though caves are generally considered as being extreme subterranean environments, in that they have limited availability of organic matter and light, have high humidity, and vary in their mineral composition, diverse bacteria can nonetheless thrive in these habitats (Northup and Lavoie, 2001). This empirical study performed an intensive analysis of bacterial communities dwelling in air, rock, sediment and water sampled from eight karst caves in southwest China. It represents an immense attempt to systematically document the pristine oligotrophic cave-associated bacteriomes. The discovery of a great number of bacteria with multiplex phylogenetic assignments will spur further investigation of microbe-involved biogeochemical processes in cave systems.

\section{Distribution Pattern of the Karst Cave Bacteriome}

All caves studied in this work are rarely accessible to tourists, so any anthropogenic impact could only come from local residents occasionally entering the caves. Besides regular nutrient sources carried in via dripping water or flooding, bat roosts were also found in the sampled caves. These caves were geographically isolated overall, yet we found that the diversity and community composition were similar among the eight caves, with the Proteobacteria, Actinobacteria, Firmicutes, Thaumarchaeota, Gemmatimonadetes, Chloroflexi, and Bacteroidetes being the most abundant taxa found. Similar results were reported for caves located in Spain, Czech Republic, and Slovenia (Schabereiter-Gurtner et al., 2004; Porca et al., 2012). All the dominant phyla identified in this study were also found in previous studies, as summarized by Hershey and Barton (2018).

However, we did find significant differences among bacterial communities in terms of their occupied niches (i.e., air, rock, sediment, and water), not unlike Brannen-Donnelly and Engel (2015) who reported that bacterial community composition in

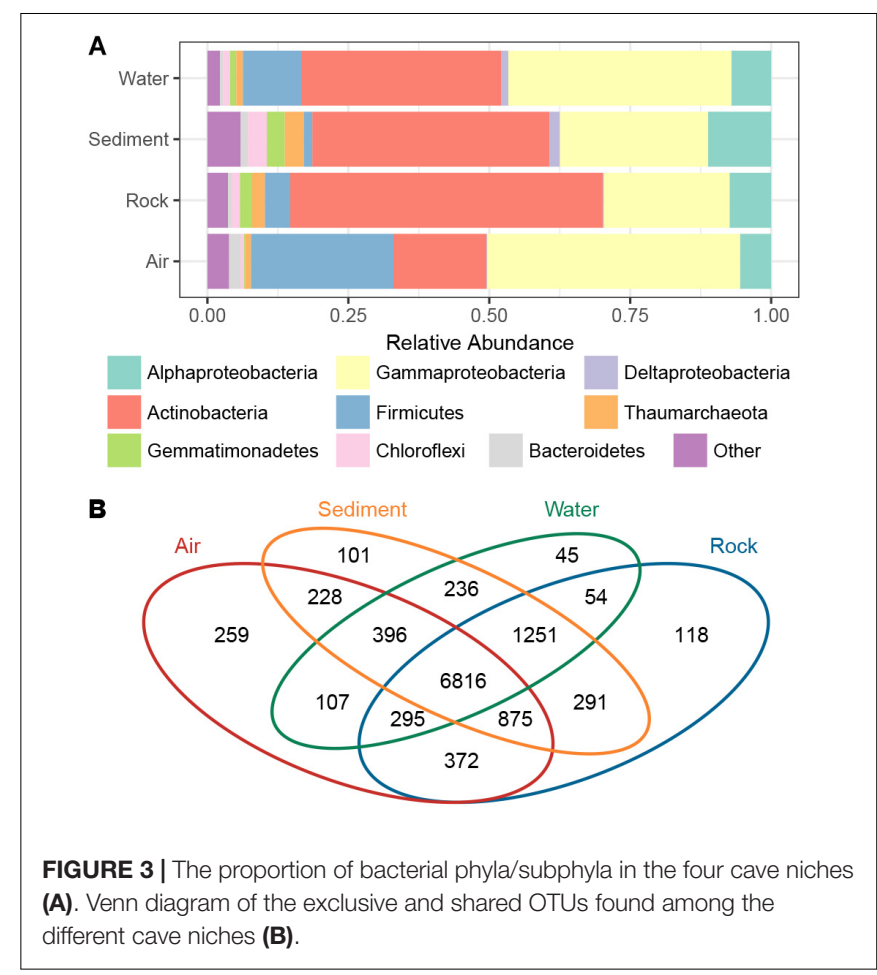

cave streams and sediments differed at the class level. More recently, Alonso et al. (2018) reported that mineral substrate was the most significant factor determining cave microbial diversity and structure. Other studies also showed that the bacterial communities associated with dripping water in the Heshang Cave in central China were mostly dominated by Proteobacteria, while Actinobacteria was the most dominant phyla in weathered rocks in the same cave (Yun et al., 2016a,b). Those findings coupled with our results, suggest that specific niches drive microbial community evolution, perhaps sustaining the enrichment of unique microbial populations, despite the general similarity of the microbial community across whole caves.

\section{Niches (Water, Air, Sediment, Rock) Enrich Specific Bacterial Groups}

Water samples in this study were collected from the cave ground surface, unlike studies that focused on bacteria in dripping water (e.g., Marques et al., 2019). In previous studies, Betaproteobacteria represented the core microbial groups occurring in karst water (Shabarova and Pernthaler, 2010; Shabarova et al., 2013; Brannen-Donnelly and Engel, 2015). Based on the latest SILVA database release 132, we found that the Betaproteobacteriales, Pseudomonadales, Pseudonocardiales, and Bacillales comprised a larger proportion of the community based on their average abundances in the cave water samples.

Bacteria dispersal in cave air is a poorly understood process. Recently, Leplat et al. (2019) monitored aerial rates of bacteria in five decorated caves for more than 2 years, yet no linear or quadratic relation was found between the distance index and the bacterial rates. In our study, the influence of sampling depth - the distance from cave entrance to sampling site - on 


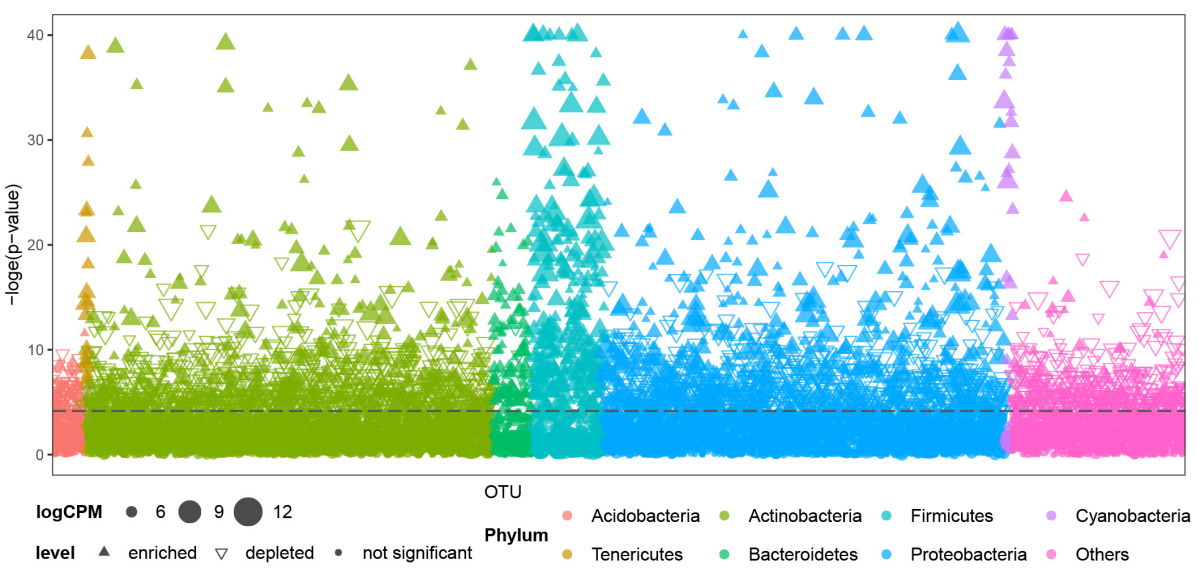

FIGURE 4 | Comparison of OTUs' distribution between air samples and other samples (niches) from caves. CPM is counts per million, the dashed line is the 95\% confidence level. Solid upward triangles are OTUs significantly enriched in air samples, hollow downward triangles are OTUs significantly depleted in air samples, solid points are those OTUs significantly unchanged in air samples compared with other types of samples. The size of triangles and points are proportional to the abundance of that OTU.

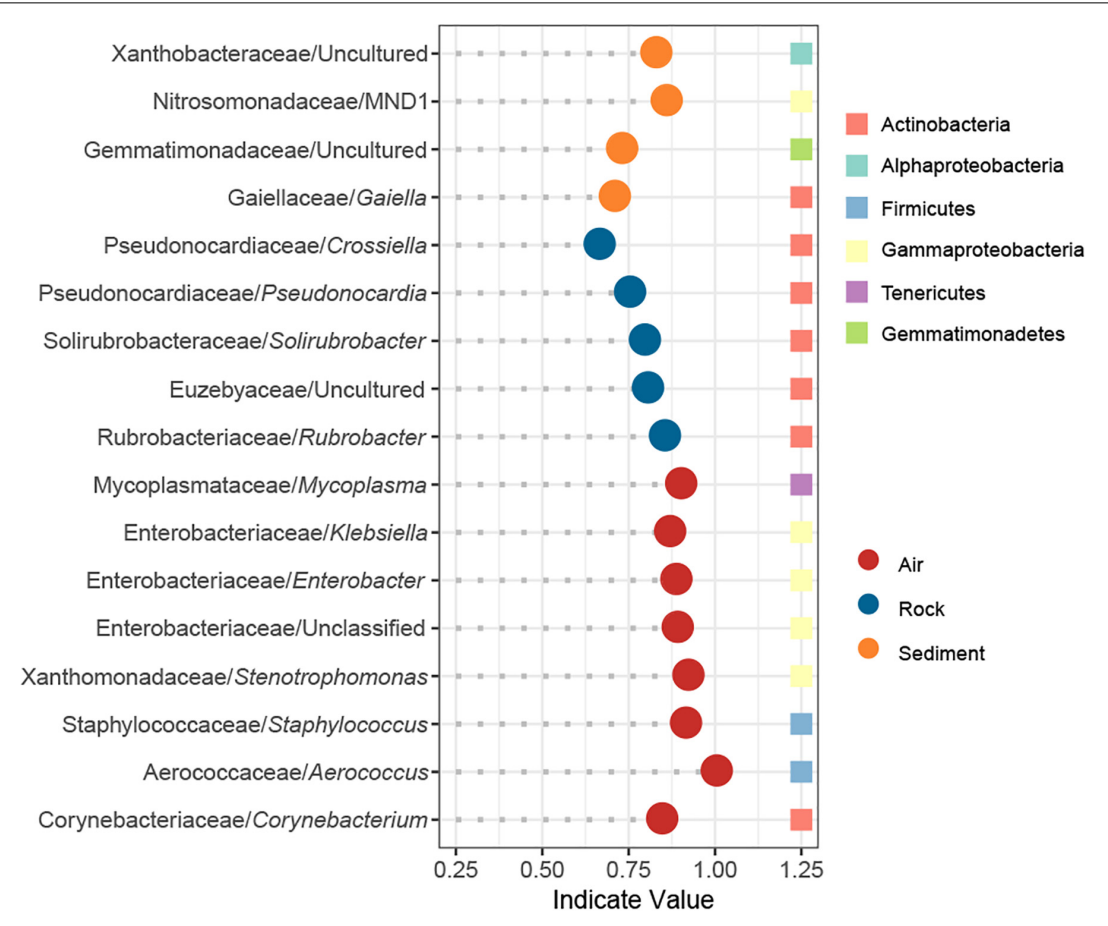

FIGURE 5 | Indicator genera of different cave niches based on an IndVal analysis. Genera with an indicator value $>0.6$ and $p<0.05$ were identified as indicators.

bacterial community was also evaluated, but no statistically significant effect of sampling depth on either alpha or beta diversity was evident. We did, however, notice that genera in Enterobacteriaceae and Staphylococcus were identified as indictor genera of air samples, and such an observation might be related to bat residency or human activity in caves (Griffin et al., 2014). Discerning the impact of human activity on cave bacterial community can be complicated. For example, Hunter et al. (2004) identified coliforms, an indicator of fecal contamination in the Lechuguilla Cave, while Johnston et al. (2012) proved that a human urine-impacted site in a cave was colonized by endemic cave species instead of human commensal organisms.

Previous studies have reported that Actinobacteria represents the most abundant member in cave sediment communities (De Mandal et al., 2015a,b), however, we found that Proteobacteria also accounted for a large number of cavedwelling bacteria. Consistent with this result, Proteobacteria, especially Gammaproteobacteria, were also prevalent in sediment samples from other caves (Barron et al., 2010; Brannen-Donnelly and Engel, 2015). Furthermore, Carmichael et al. (2013) found 


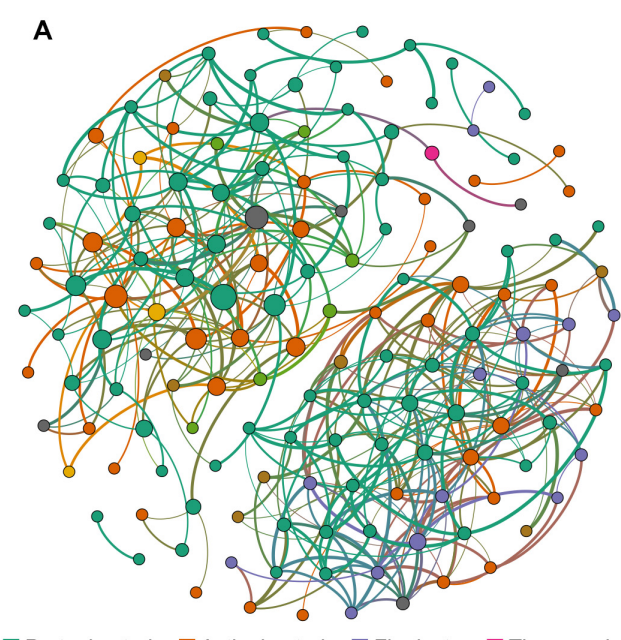

Proteobacteria Actinobacteria Firmicutes Thaumarchaeota Gemmatimonadetes Chloroflexi Bacteroidetes $\square$ Other

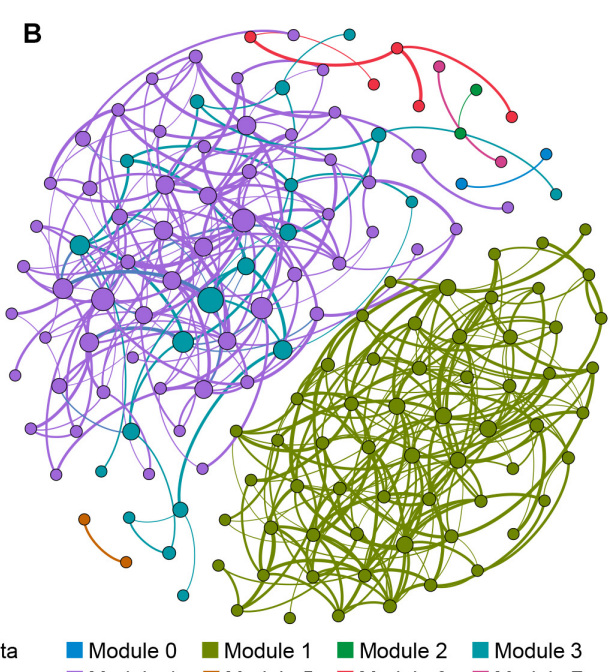

Module 4 Module 5 Module 6 Module 7

FIGURE 6 | Network of co-occurring bacterial genera based on a correlation analysis for the cave environment. A connection denotes a strong (Spearman's $\rho>0.6$ ) and significant $(p<0.01)$ correlation. The nodes in network (A) are colored according to phylum, while the nodes in network (B) are colored with respect to modularity class. Node size is proportional to the betweenness centrality of each genus, and edge thickness is proportional to the weight of each correlation.

TABLE 4 | Topological properties of co-occurring networks obtained from different karst cave niches.

\begin{tabular}{lccccccc}
\hline Cave niches & Nodes & Edges & Modularity (MD) & $\begin{array}{c}\text { Clustering } \\
\text { coefficient (CC) }\end{array}$ & $\begin{array}{c}\text { Average path } \\
\text { length (APL) }\end{array}$ & Network diameter (ND) & Average degree (AD) \\
\hline Air & 138 & 244 & 0.647 & 0.307 & 4.832 & 5.456 & 13 \\
Rock & 193 & 805 & 0.510 & 0.445 & 5.024 & 17 & 17 \\
Sediment & 186 & 751 & 0.428 & 0.501 & 5.226 & 16 & 8.342 \\
Water & 223 & 1744 & 0.406 & 0.525 & & 15.641 \\
\hline
\end{tabular}

that cave sediments contained primarily Proteobacteria when they had been influenced by water influx. In our caves, multiple factors clearly affected the community composition of their sediment samples, with moisture being the most important one (Table $3, R^{2}=0.4577, p=0.001$ ). Moisture also had a relatively strong positive association with the Shannon index in sediment samples, a result probably explained by water content being a major limitation for nutrient diffusion (Skopp et al., 1990). Interestingly, total nitrogen had a relatively strong negative relationship (Table $3, \rho=-0.5122, p=0.001$ ) with the Shannon index in sediment samples. It was reported recently that microbes in karst sediments are more limited by carbon and phosphorus than by nitrogen (Chen et al., 2019); so, it could be presumed that nitrogen sources in cave sediment may favorably enrich certain dominant taxa, thus decreasing overall species richness in the cave bacterial community.

Several studies have revealed that Proteobacteria can dominate cave rock ecosystems (Pasić et al., 2010; Engel et al., 2013; Ivanova et al., 2013; Gulecal-Pektas, 2016). We found that Actinobacteria was mostly predominant. Our results might be justified for two reasons: (1) Some of the aforementioned caves are so-called show-caves, with pre-historic paintings on their wall, whose increased availability of nutrients may lead to the dominance of Proteobacteria, as proposed by
Tomczyk-Żak and Zielenkiewicz (2016). (2) Previous studies mainly focus on the surface of cave rock (Pasić et al., 2010; Engel et al., 2013; Ivanova et al., 2013; Gulecal-Pektas, 2016), while in our study, the surface of rock samples was first washed and attention was instead focused on bacteria living inside the rock or tightly attached to it. Remarkably, Pseudonocardia was identified as an indicator genus of rock bacterial community in our study. In prior studies, Pseudonocardia was deemed a major constituent of microbial colonization on walls with Paleolithic paintings in caves (Stomeo et al., 2008, 2009) and other subterranean niches such as provided by tombs (Diaz-Herraiz et al., 2013). Together, these findings suggest that microbial outbreaks in show caves might arise from an enrichment of cave indigenous bacteria instead of extraneous ones. Consistent with those studies, Pseudonocardia was abundant in our karst caves, where it served as a reliable indicator of the rock bacterial community.

\section{Keystone Members in the Cave Bacteriome}

Association networks can provide a highly compressed and simplified version of the typically complex ecological interactions that shape bacterial communities (Eiler et al., 2011). Previous studies demonstrated that nodes with high betweenness centrality (BC) scores were particularly important for maintaining the 
connectivity of an ecological network (González et al., 2010). Nitrosococcaceae wb1-P19 (average abundances: air, 0.32\%; rock, 4.42\%; sediment, 6.15\%; water, 5.20\%), the uncultured Rokubacteriales member (average abundances: air, 0.02\%; rock, $0.14 \%$; sediment, $0.87 \%$; water, $0.32 \%$ ), and the uncultured Gaiellales member (average abundances: air, 0.17\%; rock, 1.96\%; sediment, $2.57 \%$; water, $1.40 \%$ ) were identified as the top three in terms of their BC scores in this study. We therefore hypothesize that they might play critical roles in maintaining the structure and function of karst cave communities. The wb1-P19 is a genus named after an uncultured clone obtained from cave water, and it phylogenetically clustered with a section of sulfuror nitrite-oxidizing autotrophic bacteria (Holmes et al., 2001). Rokubacteriales belongs to Candidatus Rokubacteria, whose genomes are large, with high $\mathrm{G}+\mathrm{C}$ content and the potential for nitrogen respiration (Becraft et al., 2017). Gaiellales is a deep-branching lineage of Actinobacteria, and its metabolic potential is only represented by a single cultured species, Gaiella occulta; it is predicted to reduce nitrate and to perform $\mathrm{CO}_{2}$ fixation (Severino et al., 2019). Members of Gaiellales were also found in other subterranean environment such as volcanic caves (Riquelme et al., 2015), supporting their general existence in dark cave systems.

\section{CONCLUSION}

This study provides a comprehensive assessment of the bacterial communities associated with eight karst caves in southwest China. Taking species richness and composition into account, the cave bacteriome shows similarities among the caves investigated but differs significantly among different cave niches, and different environment factors drive niche-specific bacterial assembling. Indicator genera are predicted to reflect the unique environment of each cave niche. A co-occurrence analysis suggests that cave bacterial community is well modularized, and that the

\section{REFERENCES}

Adam, D., Maciejewska, M., Naome, A., Martinet, L., Coppieters, W., Karim, L., et al. (2018). Isolation, characterization, and antibacterial activity of hardto-culture Actinobacteria from cave moonmilk deposits. Antibiotics 7:28. doi: 10.3390/antibiotics7020028

Adetutu, E. M., Krystal, T., Esamaeil, S., and Steven, B. (2012). Bacterial community survey of sediments at Naracoorte Caves, Australia. Int. J. Speleol. 41, 137-147. doi: 10.5038/1827-806X.41.2.2

Alonso, L., Creuze-des-Chatelliers, C., Trabac, T., Dubost, A., Moenne-Loccoz, Y., and Pommier, T. (2018). Rock substrate rather than black stain alterations drives microbial community structure in the passage of Lascaux Cave. Microbiome 6:216. doi: 10.1186/s40168-018-0599-9

Axenovgibanov, D. V., Voytsekhovskaya, I. V., Tokovenko, B. T., Protasov, E. S., Gamaiunov, S. V., Rebets, Y. V., et al. (2016). Actinobacteria isolated from an underground lake and moonmilk speleothem from the biggest conglomeratic karstic cave in Siberia as sources of novel biologically active compounds. PloS One 11:e0149216. doi: 10.1371/journal.pone.0149216

Barberán, A., Bates, S. T., Casamayor, E. O., and Fierer, N. (2011). Using network analysis to explore co-occurrence patterns in soil microbial communities. ISME J. 6, 343-351. doi: 10.1038/ismej.2011.119 identified keystone genera might play a critical role in carbon and nitrogen, as well as sulfur, biogeochemical cycles, thus providing a new perspective on microbial assembly in cave ecosystems. Networks of the four types of samples (corresponding to four niches for bacterial taxa) showed different topological properties, arising from the distinct co-occurrence patterning of bacterial communities in each cave niche.

\section{DATA AVAILABILITY}

Raw sequence reads of the $16 \mathrm{~S}$ rRNA gene amplicon were deposited in the NCBI Sequence Read Archive (SRA) under project accession number PRJNA497480.

\section{AUTHOR CONTRIBUTIONS}

$\mathrm{H}-\mathrm{ZZ}$ carried out the experiments, analyzed the data, and wrote the manuscript. Z-FZ collected the samples and performed the experiments. NZ and B-JW conducted part of the lab work. C-YJ, LC, and S-JL designed the experimental plan. S-JL polished the manuscript.

\section{FUNDING}

This study was financially supported by the Project for Fundamental Research on Science and Technology, Ministry of Science and Technology of China (Grant No. 2014FY120100).

\section{SUPPLEMENTARY MATERIAL}

The Supplementary Material for this article can be found online at: https://www.frontiersin.org/articles/10.3389/fmicb. 2019.01726/full\#supplementary-material

Barron, S. K., Murdock, C. A., Blair, B. G., Meade, M. E., and Barger, T. W. (2010). Analysis of bacterial diversity in soils from Blowing Spring Cave (Lauderdale County, AL). J. Ala. Acad. Sci. 81, 1-10.

Barton, H. A., and Jurado, V. (2007). What's up down there? Microbial diversity in caves. Microbe 2, 132-138.

Barton, H. A., Taylor, M. R., and Pace, N. R. (2004). Molecular phylogenetic analysis of a bacterial community in an oligotrophic cave environment. Geomicrobiol. J. 21, 11-20. doi: 10.1080/0149045049025 3428

Baselga, A., and Orme, C. D. L. (2012). betapart: an R package for the study of beta diversity. Methods Ecol. Evol. 3, 808-812. doi: 10.1111/j.2041-210X.2012.00 224.x

Baskar, S. (2014). A summary of some microbes identified from different Indian caves and their possible role in mineral formations. Ambient Science 1, 9-16. doi: 10.21276/ambi.2014.01.2.rv01

Bastian, M., Heymann, S., and Jacomy, M. (2009). "Gephi: An Open Source Software for Exploring and Manipulating Networks," in Proceedings of the Third International AAAI Conference on Weblogs and Social Media, San Jose, CA.

Becraft, E. D., Woyke, T., Jarett, J., Ivanova, N., Godoy-Vitorino, F., Poulton, N., et al. (2017). Rokubacteria: genomic giants among the uncultured bacterial phyla. Front. Microbiol. 8:2264. doi: 10.3389/fmicb.2017.02264 
Bissett, A., Brown, M. V., Siciliano, S. D., and Thrall, P. H. (2013). Microbial community responses to anthropogenically induced environmental change: towards a systems approach. Ecol. Lett. 16, 128-139. doi: 10.1111/ele.12109

Brannen-Donnelly, K., and Engel, A. S. (2015). Bacterial diversity differences along an epigenic cave stream reveal evidence of community dynamics, succession, and stability. Front. Microbiol. 6:729. doi: 10.3389/fmicb.2015.00729

Cáceres, M. D., and Legendre, P. (2009). Associations between species and groups of sites: indices and statistical inference. Ecology 90, 3566-3574. doi: 10.1890/ 08- 1823.1

Cáceres, M. D., Legendre, P., and Moretti, M. (2010). Improving indicator species analysis by combining groups of sites. Oikos 119, 1674-1684. doi: 10.1111/j. 1600-0706.2010.18334.x

Cáceres, M. D., Legendre, P., Wiser, S. K., and Brotons, L. (2012). Using species combinations in indicator value analyses. Methods Ecol. Evol. 3, 973-982. doi: 10.1111/j.2041-210X.2012.00246.x

Cáceres, M. D., Sol, D., Lapiedra, O., and Legendre, P. (2011). A framework for estimating niche metrics using the resemblance between qualitative resources. Oikos 120, 1341-1350. doi: 10.1111/j.1600-0706.2011.19679.x

Caporaso, J. G., Kuczynski, J., Stombaugh, J., Bittinger, K., Bushman, F. D., Costello, E. K., et al. (2010). QIIME allows analysis of highthroughput community sequencing data. Nat. Methods 7, 335-336. doi: 10.1038/nmeth.f.303

Caporaso, J. G., Lauber, C. L., Walters, W. A., Berg-Lyons, D., Lozupone, C. A., Turnbaugh, P. J., et al. (2011). Global patterns of 16 S rRNA diversity at a depth of millions of sequences per sample. Proc. Nat. Acad. Sci. U.S.A. 108, 4516-4522. doi: $10.1073 /$ pnas. 1000080107

Carmichael, M. J., Carmichael, S. K., Santelli, C. M., Strom, A., and Bräuer, S. L. (2013). Mn (II)-oxidizing bacteria are abundant and environmentally relevant members of ferromanganese deposits in caves of the upper Tennessee River Basin. Geomicrobiol. J. 30, 779-800. doi: 10.1080/01490451.2013.76 9651

Chen, C. (2003). Evaluation of air oven moisture content determination methods for rough rice. Biosyst. Eng. 86, 447-457. doi: 10.1016/j.biosystemseng.2003.08.010

Chen, H., and Boutros, P. C. (2011). VennDiagram: a package for the generation of highly-customizable Venn and Euler diagrams in R. BMC Bioinformatics 12:35. doi: 10.1186/1471-2105-12-35

Chen, H., Li, D., Mao, Q., Xiao, K., and Wang, K. (2019). Resource limitation of soil microbes in karst ecosystems. Sci. Total Environ. 650, 241-248. doi: 10.1016/j.scitotenv.2018.09.036

Cloutier, M. L. C., Carmichael, S. K., Carson, M. A., Madritch, M. D., and Bräuer, S. L. (2017). Carbon quantity and quality drives variation in cave microbial communities and regulates $\mathrm{Mn}(\mathrm{II})$ oxidation. Biogeochemistry 134, 77-94. doi: 10.1007/s10533-017-0343-8

Csardi, G., and Nepusz, T. (2006). The igraph software package for complex network research. Interjournal Complex Syst. 2006:1695.

Cunningham, K. I., Northup, D. E., Pollastro, R. M., Wright, W. G., and Larock, E. J. (1995). Bacteria, fungi and biokarst in Lechuguilla Cave, Carlsbad Caverns National Park, New Mexico. Environ. Geol. 25, 2-8. doi: 10.1007/bf0106 1824

Danielli, H. M. C., and Edington, M. A. (1983). Bacterial calcification in limestone caves. Geomicrobiol. J. 3, 1-16. doi: 10.1080/01490458309377780

De Mandal, S., Panda, A. K., Lalnunmawii, E., Bisht, S. S., and Kumar, N. S. (2015a). Illumina-based analysis of bacterial community in Khuangcherapuk cave of Mizoram, Northeast India. Genom. Data 5, 13-14. doi: 10.1016/j.gdata.2015. 04.023

De Mandal, S., Sanga, Z., and Senthil Kumar, N. (2015b). Metagenome sequencing reveals Rhodococcus dominance in Farpuk Cave, Mizoram, India, an Eastern Himalayan biodiversity hot spot region. Genome Announc. 3, e610-e615. doi: 10.1128/genomeA.00610-15

Diaz-Herraiz, M., Jurado, V., Cuezva, S., Laiz, L., Pallecchi, P., Tiano, P., et al. (2013). The actinobacterial colonization of Etruscan paintings. Sci. Rep. 3:1440. doi: $10.1038 /$ srep01440

Edgar, R. C. (2010). Search and clustering orders of magnitude faster than BLAST. Bioinformatics 26, 2460-2461. doi: 10.1093/bioinformatics/btq461

Eiler, A., Heinrich, F., and Bertilsson, S. (2011). Coherent dynamics and association networks among lake bacterioplankton taxa. ISME J. 6, 330-342. doi: 10.1038/ ismej.2011.113
Engel, A. S., Paoletti, M. G., Beggio, M., Dorigo, L., Pamio, A., and Gomiero, T. (2013). Comparative microbial community composition from secondary carbonate (moonmilk) deposits: implications for the Cansiliella servadeii cave hygropetric food web. Int. J. Speleol. 42, 181-192. doi: 10.5038/1827806X.42.3.2

Ford, D. C., and Williams, P. W. (1989). Karst Geomorphology and Hydrology. London: Unwin Hyman.

Gabriel, C. R., and Northup, D. E. (2013). Microbial ecology: caves as an extreme habitat. Springerbriefs in Microbiology 1, 85-108. doi: 10.1007/978-1-46145206-5_5

Ghosh, S., Kuisiene, N., and Cheeptham, N. (2017). The cave microbiome as a source for drug discovery: reality or pipe dream? Biochem. Pharmacol. 134, 18-34. doi: 10.1016/j.bcp.2016.11.018

González, A. M. M., Bo, D., and Olesen, J. M. (2010). Centrality measures and the importance of generalist species in pollination networks. Ecol. Complex. 7, 36-43. doi: 10.1016/j.ecocom.2009.03.008

Griffin, D. W., Gray, M. A., Lyles, M. B., and Northup, D. E. (2014). The transport of nonindigenous microorganisms into caves by human visitation: a case study at Carlsbad Caverns National Park. Geomicrobiol. J. 31, 175-185. doi: 10.1080/ 01490451.2013 .815294

Gulecal-Pektas, Y. (2016). Bacterial diversity and composition in Oylat Cave (Turkey) with combined Sanger/pyrosequencing approach. Pol. J. Microbiol. 65, 69-75. doi: 10.5604/17331331.1197277

He, S., Guo, L., Niu, M., Miao, F., Jiao, S., Hu, T., et al. (2017). Ecological diversity and co-occurrence patterns of bacterial community through soil profile in response to long-term switchgrass cultivation. Sci. Rep. 7:3608. doi: 10.1038/ s41598-017-03778-7

Hershey, O. S., and Barton, H. A. (2018). “The microbial diversity of caves," in Cave Ecology, eds O. T. Moldovan, Kováč, and S. Halse (New York, NY: Springer), 69-90. doi: 10.1007/978-3-319-98852-8_5

Holmes, A. J., Tujula, N. A., Holley, M., Contos, A., James, J. M., Rogers, P., et al. (2001). Phylogenetic structure of unusual aquatic microbial formations in Nullarbor Caves, Australia. Environ. Microbiol. 3, 256-264. doi: 10.1046/j. 1462-2920.2001.00187.x

Hunter, A. J., Northup, D. E., Dahm, C. N., and Boston, P. J. (2004). Persistent coliform contamination in Lechuguilla Cave pools. J. Cave Karst Stud. 66, $102-110$.

Ivanova, V., Tomova, I., Kamburov, A., Tomova, A., Vasileva-Tonkova, E., and Kambourova, M. (2013). High phylogenetic diversity of bacteria in the area of prehistoric paintings in Magura Cave, Bulgaria. J. Cave Karst Stud. 75, 218-228. doi: 10.4311/2012MB0279

Jiao, S., Liu, Z., Lin, Y., Yang, J., Chen, W., and Wei, G. (2016). Bacterial communities in oil contaminated soils: biogeography and co-occurrence patterns. Soil Biol. Biochem. 98, 64-73. doi: 10.1016/j.soilbio.2016.04.005

Johnston, M. D., Muench, B. A., Banks, E. D., and Barton, H. A. (2012). Human urine in Lechuguilla Cave: the microbiological impact and potential for bioremediation. J. Cave Karst Stud. 74, 278-291. doi: 10.4311/2011MB0227

Jones, D. S., Albrecht, H. L., Dawson, K. S., Schaperdoth, I., Freeman, K. H., $\mathrm{Pi}$, Y., et al. (2012). Community genomic analysis of an extremely acidophilic sulfur-oxidizing biofilm. ISME J. 6, 158-170. doi: 10.1038/ismej.2011.75

Jones, D. S., Schaperdoth, I., and Macalady, J. L. (2014). Metagenomic evidence for sulfide oxidation in extremely acidic cave biofilms. Geomicrobiol. J. 31, 194-204. doi: 10.1080/01490451.2013.834008

Jones, D. S., Tobler, D. J., Schaperdoth, I., Mainiero, M., and Macalady, J. L. (2010). Community structure of subsurface biofilms in the thermal sulfidic caves of Acquasanta Terme, Italy. Appl. Environ. Microbiol. 76, 5902-5910. doi: 10.1128/aem.00647-10

Laiz, L., Groth, I., Gonzalez, I., and Saiz-Jimenez, C. (1999). Microbiological study of the dripping waters in Altamira cave (Santillana del Mar, Spain). J. Microbiol. Meth. 36, 129-138. doi: 10.1016/S0167-7012(99)00018-4

Legatzki, A., Ortiz, M., Neilson, J. W., Dominguez, S., Andersen, G. L., Toomey, R. S., et al. (2011). Bacterial and archaeal community structure of two adjacent calcite speleothems in Kartchner Caverns, Arizona, USA. Geomicrobiol. J. 28, 99-117. doi: 10.1080/01490451003738465

Leplat, J., Francois, A., Touron, S., Galant, P., and Bousta, F. (2019). Aerobiological behavior of Paleolithic decorated caves: a comparative study of five caves in the Gard department (France). Aerobiologia 35, 105-124. doi: 10.1007/s10453-0189546-2 
Lewin-Koh, N., Bivand, R., Pebesma, E., Archer, E., Baddeley, A., Bibiko, H.-J., et al. (2011). maptools: Tools for Reading and Handling Spatial Objects. Available at: https://CRAN.R-project.org/package=maptools (accessed February 18, 2019).

Liu, Q., Wang, H., Zhao, R., Qiu, X., and Gong, L. (2010). Bacteria isolated from dripping water in the oligotrophic Heshang cave in Central China. J. Earth Sci. 21, 325-328. doi: 10.1007/s12583-010-0250-6

Marques, E. L. S., Silva, G. S., Dias, J. C. T., Gross, E., Costa, M. S., and Rezende, R. P. (2019). Cave drip water-related samples as a natural environment for aromatic hydrocarbon-degrading bacteria. Microorganisms 7:33. doi: 10.3390/ microorganisms 7020033

Newman, M. (2003). The structure and function of complex networks. SIAM Rev. 45, 167-256. doi: 10.1137/S003614450342480

Newman, M. E. J. (2006). Modularity and community structure in networks. Proc. Nat. Acad. Sci. U.S.A. 103:8577. doi: 10.1073/pnas.0601602103

Nguyễn-Thuý, D., Schimmelmann, A., Nguyễn-Vãn, H., Drobniak, A., Lennon, J. T., Tạ, P. H., et al. (2017). Subterranean microbial oxidation of atmospheric methane in cavernous tropical karst. Chem. Geol. 466, 229-238. doi: 10.1016/j. chemgeo.2017.06.014

Northup, D. E., and Lavoie, K. H. (2001). Geomicrobiology of caves: a review. Geomicrobiol. J. 18, 199-222. doi: 10.1080/01490450152467750

Ortiz, M., Neilson, J. W., Nelson, W. M., Legatzki, A., Byrne, A., Yu, Y., et al. (2013). Profiling bacterial diversity and taxonomic composition on speleothem surfaces in Kartchner Caverns, AZ. Microb. Ecol. 65, 371-383. doi: 10.1007/s00248-0120143-6

Pasić, L., Kovce, B., Sket, B., and Herzogvelikonja, B. (2010). Diversity of microbial communities colonizing the walls of a karstic cave in Slovenia. FEMS Microbiol. Ecol. 71, 50-60. doi: 10.1111/j.1574-6941.2009.00789.x

Paulson, J. N., Stine, O. C., Bravo, H. C., and Pop, M. (2013). Differential abundance analysis for microbial marker-gene surveys. Nat. Methods 10, 1200-1202. doi: 10.1038/nmeth. 2658

Porca, E., Jurado, V., Žgur-Bertok, D., Saiz-Jimenez, C., and Pašić, L. (2012). Comparative analysis of yellow microbial communities growing on the walls of geographically distinct caves indicates a common core of microorganisms involved in their formation. FEMS Microbiol. Ecol. 81, 255-266. doi: 10.1111/j. 1574-6941.2012.01383.x

Pruesse, E., Peplies, J., and Glöckner, F. O. (2012). SINA: accurate high-throughput multiple sequence alignment of ribosomal RNA genes. Bioformatics 28, 1823-1829. doi: 10.1093/bioinformatics/bts252

Quast, C., Pruesse, E., Yilmaz, P., Gerken, J., Schweer, T., Yarza, P., et al. (2013). The SILVA ribosomal RNA gene database project: improved data processing and web-based tools. Nucl. Acids Res. 41, D590-D596. doi: 10.1093/nar/gks1219

Revelle, W. (2018). Psych: Procedures for Personality and Psychological Research. Evanston, IL: Northwestern University.

Riquelme, C., Marshall Hathaway, J. J., Enes Dapkevicius, M. L. N., Miller, A. Z., Kooser, A., Northup, D. E., et al. (2015). Actinobacterial diversity in volcanic caves and associated geomicrobiological interactions. Front. Microbiol. 6:1342. doi: $10.3389 /$ fmicb. 2015.01342

Robinson, M. D., Mccarthy, D. J., and Smyth, G. K. (2010). edgeR: a bioconductor package for differential expression analysis of digital gene expression data. Bioinformatics 26, 139-140. doi: 10.1093/bioinformatics/btp616

Ruibal, C., Platas, G., and Bills, G. F. (2005). Isolation and characterization of melanized fungi from limestone formations in Mallorca. Mycol. Prog. 4, 23-38. doi: 10.1007/s11557-006-0107-7

Sarbu, S. M., Kane, T. C., and Kinkle, B. K. (1996). A chemoautotrophically based cave ecosystem. Science 272, 1953-1955. doi: 10.1126/science.272.5270. 1953

Schabereiter-Gurtner, C., Saiz-Jimenez, C., Piñar, G., Lubitz, W., and Rölleke, S. (2004). Phylogenetic diversity of bacteria associated with Paleolithic paintings and surrounding rock walls in two Spanish caves (Llonín and La Garma). FEMS Microbiol. Ecol. 47, 235-247. doi: 10.1016/S0168-6496(03)00280-0

Severino, R., Froufe, H. J. C., Barroso, C., Albuquerque, L., Lobo-da-Cunha, A., da Costa, M. S., et al. (2019). High-quality draft genome sequence of Gaiella occulta isolated from a 150 meter deep mineral water borehole and comparison with the genome sequences of other deep-branching lineages of the phylum Actinobacteria. Microbiol. Open e840. doi: 10.1002/mbo3.840

Shabarova, T., and Pernthaler, J. (2010). Karst pools in subsurface environments: collectors of microbial diversity or temporary residence between habitat types. Environ. Microbiol. 12, 1061-1074. doi: 10.1111/j.1462-2920.2009.02151.x

Shabarova, T., Widmer, F., and Pernthaler, J. (2013). Mass effects meet species sorting: transformations of microbial assemblages in epiphreatic subsurface karst water pools. Environ. Microbiol. 15, 2476-2488. doi: 10.1111/1462-2920. 12124

Skopp, J., Jawson, M. D., and Doran, J. W. (1990). Steady-state aerobic microbial activity as a function of soil water content. Soil Sci. Soc. Am. J. 54, 1619-1625. doi: 10.2136/sssaj1990.03615995005400060018x

Sparks, D., Page, A., Helmke, P., and Loeppert, R. (1996). Methods of Soil Analysis. Part 3. Madison, WI: Soil Science Society of America.

Stomeo, F., Portillo, M. C., and Gonzalez, J. M. (2009). Assessment of bacterial and fungal growth on natural substrates: consequences for preserving caves with prehistoric paintings. Curr. Microbiol. 59, 321-325. doi: 10.1007/s00284-0099437-4

Stomeo, F., Portillo, M. C., Gonzalez, J. M., Laiz, L., and Saiz-Jimenez, C. (2008). Pseudonocardia in white colonizations in two caves with Paleolithic paintings. Int. Biodeter. Biodegr. 62, 483-486. doi: 10.1016/j.ibiod.2007.12.011

Strimmer, K. (2008a). A unified approach to false discovery rate estimation. BMC Bioinformatics 9:303. doi: 10.1186/1471-2105-9-303

Strimmer, K. (2008b). fdrtool: a versatile R package for estimating local and tail area-based false discovery rates. Bioinformatics 24, 1461-1462. doi: 10.1093/ bioinformatics/btn209

Tomczyk-Żak, K., and Zielenkiewicz, U. (2016). Microbial diversity in caves. Geomicrogiol. J. 33, 1-19. doi: 10.1080/01490451.2014.1003341

Watts, D. J., and Strogatz, S. H. (1998). Collective dynamics of 'small-world' networks. Nature 393, 440-442. doi: 10.1038/30918

Webster, K. D., Drobniak, A., Etiope, G., Mastalerz, M., Sauer, P. E., and Schimmelmann, A. (2018). Subterranean karst environments as a global sink for atmospheric methane. Earth Planet. Sci. Lett. 485, 9-18. doi: 10.1016/j.epsl. 2017.12.025

Wickham, H. (2009). ggplot2: Elegant Graphics for Data Analysis. New York, NY: Springer.

Wu, Y., Tan, L., Liu, W., Wang, B., Wang, J., Cai, Y., et al. (2015). Profiling bacterial diversity in a limestone cave of the western Loess Plateau of China. Front. Microbiol. 6:244. doi: 10.3389/fmicb.2015.00244

Yilmaz, P., Parfrey, L. W., Yarza, P., Gerkan, J., Pruesse, E., Quast, C., et al. (2014). The SILVA and "all-species living tree project (LTP)" taxonomic frameworks. Nucl. Acids Res. 42, D643-D648. doi: 10.1093/nar/gkt1209

Yun, Y., Wang, H., Man, B., Xiang, X., Zhou, J., Qiu, X., et al. (2016a). The relationship between $\mathrm{pH}$ and bacterial communities in a single karst ecosystem and its implication for soil acidification. Front. Microbiol. 7:1955. doi: 10.3389/ fmicb.2016.01955

Yun, Y., Xiang, X., Wang, H., Man, B., Gong, L., Liu, Q., et al. (2016b). Five-year monitoring of bacterial communities in dripping water from the Heshang Cave in Central China: implication for paleoclimate reconstruction and ecological functions. Geomicrobiol. J. 33, 553-563. doi: 10.1080/01490451.2015.1062062

Zhang, J., Kobert, K., Flouri, T., and Stamatakis, A. (2014). PEAR: a fast and accurate Illumina Paired-End reAd mergeR. Bioinformatics 30, 614-620. doi: 10.1093/bioinformatics/btt593

Zhang, Y., and Zhu, D. (2012). The distribution and evolution of China's big karst caves. J. Guilin University of Technology 32, 20-28. doi: 10.3969/j.issn.16749057.2012.01.003

Zhang, Z., and Cai, L. (2019). Substrate and spatial variables are major determinants of fungal community in karst caves in Southwest China. J. Biogeogr. 46, 1504-1518. doi: 10.1111/jbi.13594

Zhao, R., Wang, H., Cheng, X., Yun, Y., and Qiu, X. (2018). Upland soil cluster gamma dominates the methanotroph communities in the karst Heshang Cave. FEMS Microbiol. Ecol. 94:fiy192. doi: 10.1093/femsec/fiy192

Zhou, J., Deng, Y., Luo, F., He, Z., and Yang, Y. (2011). Phylogenetic molecular ecological network of soil microbial communities in response to elevated $\mathrm{CO} 2$. MBio 2, e00122-111. doi: 10.1128/mBio.00122-11

Conflict of Interest Statement: The authors declare that the research was conducted in the absence of any commercial or financial relationships that could be construed as a potential conflict of interest.

Copyright (c) 2019 Zhu, Zhang, Zhou, Jiang, Wang, Cai and Liu. This is an openaccess article distributed under the terms of the Creative Commons Attribution License (CC BY). The use, distribution or reproduction in other forums is permitted, provided the original author(s) and the copyright owner(s) are credited and that the original publication in this journal is cited, in accordance with accepted academic practice. No use, distribution or reproduction is permitted which does not comply with these terms. 